\title{
Preferência Revelada e Arbitragem Espacial: Determinando um Ranking de Qualidade de Vida para as Regióes Metropolitanas do Brasil*
}

\author{
Raul da Mota Silveira Neto ${ }^{\dagger}$, Tatiane Almeida de Menezes ${ }^{\ddagger}$
}

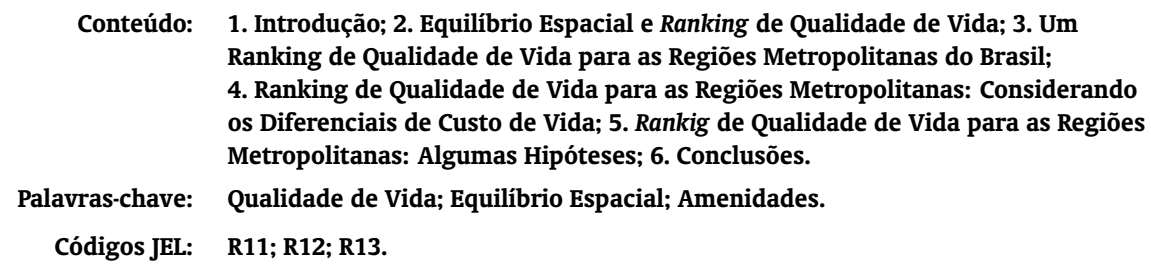

O artigo propõe extensões da metodologia de Kahn (1995) para determinação de um ranking de qualidade de vida para um conjunto de localidades, aplicando-as ao conjunto de regiões metropolitanas do Brasil a partir de microdados da Pesquisa Nacional por Amostra de Domicílio (PNAD) do ano de 2004, depois de corrigir os salários regionais através do Índice de Custo de Vida proposto por Azzoni et alii (2000). As propostas eliminam grande parte das fragilidades envolvidas na construção de índices de qualidade de vida a partir de estimações de preços hedônicos e consideram os diferenciais regionais de preços dos bens e serviços comercializáveis entre as localidades. No sentido de apontar a consistência dos resultados obtidos com algumas hipóteses levantadas, o ranking obtido para 2004 é cotejado com aquele de 1993.

Based in the seminal work of Kahn (1995), the article proposes new methodologies to rank localities in terms of quality of life, applying them to the set of Brazilian metropolitan regions with data from Pesquisa Nacional por Amostra de Domicílio (PNAD) of the year of 2004, after controlling for regional disparities of cost of life by using Azzoni et alii (2000) Price Index. The new proposals

\footnotetext{
* Os autores agradecem as críticas e sugestões de dois pareceristas da revista e assumem responsabilidade por possíveis erros e omissões remanescentes.

$\dagger^{\dagger}$ Depto. de Economia - UFPE, PIMES. Pesquisador do CNPq. Rua Bartolomeu de Gusmão, 62/201, Madalena, Recife - PE - CEP 50610-190. E-mail: rau.silveira@uol.com.br

${ }^{\ddagger}$ Depto. de Economia - UFPE, PIMES. Pesquisadora do CNPq. E-mail: tatianedemenezes@terra. com.br
} 
eliminate most of fragilities in building life quality indices from estimation of hedonic prices and take in account regional difference in prices of good and services tradable among regions. To highlight the consistency of the results, additional evidence for the year of 1993 is supplied.

\section{INTRODUÇÃO}

De acordo com a Pesquisa Nacional por Amostra de Domicílios de 2004, mesmo depois de descontadas as diferenças quanto a atributos pessoais e ocupacionais, os indivíduos residentes na região metropolitana do Rio de Janeiro poderiam ter, em média, uma renda mensal do trabalho cerca de $14 \%$ maior caso desenvolvessem sua ocupação na região metropolitana de São Paulo. Além disto, tal ganho potencial se mantém elevado (em torno de $11 \%$ ) quando tal estimativa é feita para o quantil 0,9 da distribuição condicional de renda do trabalho, ou seja, mesmo quando se consideram as disparidades entre os indivíduos mais bem postos nos mercados de trabalho, o que indica que dificilmente estes diferenciais identificados podem ser atribuídos a dificuldades de arbitragem locacional (custos de transportes, por exemplo). Em verdade, dadas as conhecidas disparidades entre estes centros urbanos brasileiros com respeito às amenidades naturais, estas evidências sugerem que os diferenciais apontados podem representar um preço pago pelos nativos do Rio de Janeiro por residirem em um local naturalmente mais ameno.

De fato, desde o trabalho de Rosen (1979) sobre os diferenciais compensatórios de salários e da análise destes diferenciais sob equilíbrio geral por Roback (1982), os economistas têm uma explicação para as disparidades salariais entre localidades sujeitas a distintos níveis de amenidades ou bens públicos: as diferenças de remunerações entre as localidades, observadas mesmo para indivíduos igualmente produtivos, refletiriam os diferentes níveis de disponibilidades destas amenidades ou bem públicos nas localidades, de forma que, sob equilíbrio (inexistência de ganhos com arbitragem locacional), as localidades mais bem (mal) servidas com respeito às referidas amenidades apresentariam menores (maiores) remunerações para os seus residentes.Em conformidade, também de forma pioneira, Roback (1988) mostrou que as disparidades de renda entre trabalhadores de diferentes regiões americanas tornam-se insignificantes quando tais diferenças são condicionadas por um conjunto de amenidades naturais e sociais.

A partir da contribuição seminal destes autores e da associação das diferentes disponibilidades locais de amenidades naturais e sociais a diferentes níveis de qualidade de vida das cidades ou centro urbanos, uma série de trabalhos passou a estabelecer rankings de qualidade de vida para diferentes conjuntos de localidades (Blomquist et alii, 1988, Beeson e Eberts, 1989, Gyourko e Tracy, 1991, Gyourko et alii, 1997, Srinivasan e Stewart, 2004, Blomquist, 2005).

No Brasil, a despeito da dimensão continental do país e das conhecidas heterogeneidades geográficas de seus centros urbanos, são ainda escassas as evidências disponíveis na literatura nesta área. Contudo, tal situação tem sido recentemente revertida; com efeito, Monte (2004), por exemplo, a partir de dados da Pesquisa de Orçamento Familiar (POF) para 11 cidades brasileiras, estima a valoração monetária de um conjunto de amenidades naturais (temperatura média, distância do mar, intensidade de chuvas, etc.) por parte dos residentes destas cidades. Por sua vez, da Mata et alii (2006) utiliza uma série de indicadores de amenidades sociais (indicadores de serviços de infraestrutura domiciliar, de acesso a serviços de educação e de saúde) para apontar diferenças de qualidade de vida entre as cidades brasileiras.

Por considerarem exclusivamente amenidades naturais (Monte, 2004) ou amenidades sociais (da Mata et alii, 2006), estes dois últimos trabalhos citados fornecem quadros parciais a respeito dos diferenciais de qualidade de vidas das cidades ou centros urbanos brasileiros, não permitindo, efetivamente, uma ordenação das localidades consideradas. O objetivo deste artigo é, pois, estabelecer um ranking de qualidade de vida para as regiões metropolitanas do Brasil considerando simultaneamente as influências de amenidades naturais e sociais no bem-estar dos indivíduos e os diferenciais de custo de vida 
entre tais regiões. Para tal, em vista das dificuldades presentes nas estimações de preços hedônicos, são propostas duas extensões da metodologia de Kahn (1995), onde a ordenação das localidades de acordo com a qualidade de vida é obtida através de preferências reveladas pelos indivíduos, estas últimas sendo obtidas através da mensuração dos ganhos potenciais com a migração dos indivíduos para diferentes localidades.

Além desta introdução, o artigo foi organizado em mais quatro seções. Na próxima, tendo-se como referência a arbitragem e o equilíbrio espacial, são apresentadas e analisadas formas alternativas de obtenção de rankings de qualidade de vida para um conjunto de localidades, o que inclui a contribuição metodológica proposta neste artigo. Na seção três, são apresentados os resultados das estimativas das equações utilizadas e o ranking de qualidade de vida para as regiões metropolitanas (RMs) do Brasil no ano de 2004. Em seguida, na seção 4, são feitas correções nas estimativas no sentido de considerar a influência dos diferenciais de custo de vida entre as RMs do país, obtendo-se uma nova ordenação. $\mathrm{Na}$ seção 5, no sentido de apontar a consistência dos resultados com algumas hipóteses levantadas, primeiro, são estimados os ganhos potenciais com a migração para as regiões metropolitanas mais bem classificadas (Recife, Fortaleza, e Rio de Janeiro). Em seguida, o ranking obtido em 2004 é confrontado com aquele obtido para o ano de 1993. As conclusões do artigo são apresentadas na sexta e última seção.

\section{EQUILÍBRIO ESPACIAL E RANKING DE QUALIDADE DE VIDA}

As diferentes formas de ordenar um conjunto de localidades ou centros urbanos de acordo com a qualidade de vida de seus respectivos ambientes apresentam uma congruência: são economicamente fundamentadas na noção de equilíbrio espacial, garantido pela arbitragem dos indivíduos e firmas quanto ao local de residência e localização produtiva. Desta forma, nesta seção é apresentada inicialmente tal estrutura espacial de equilíbrio, seguindo-se de perto a proposta de Roback $(1982,1988)$. Em seguida, são apresentadas e discutidas formas alternativas de ordenação das localidades de acordo com a qualidade de vida, enfatizando-se a nova proposta sugerida neste artigo.

Neste sentido, assuma-se, pois, a existência de diversas localidades com diferentes dotações de amenidades (positivas e negativas) a. Além deste conjunto de amenidades, o bem-estar dos residentes é afetado também pelos níveis de consumo de um bem tradeble (entre as localidades) composto, $X$, com preço fixado nacionalmente e tomado como numerário, e por um bem ou serviço local nontradeble (serviços de moradia). A produção, sob retornos constantes de escala e influenciada por amenidades locais, é obtida com utilização de trabalho e serviços do bem local, $L$. Há livre mobilidade do fator trabalho entre as diferentes localidades e os serviços dos fatores locais são fixos para cada localidade.

Em tal contexto, o problema do trabalhador/consumidor é escolher níveis de consumo de $X$ e $L$ que maximize bem-estar e satisfaça sua restrição orçamentária, sendo tais escolhas condicionadas pela disponibilidade de amenidades de sua localidade, $a$. Já o problema da firma pode ser colocado em termos de obtenção de um mínimo custo de produção sujeito à sua função de produção. Uma representação do equilíbrio para estes dois agentes representativos pode ser colocada em termos da função utilidade indireta $(V)$ e da função custo $(c)$, respectivamente, na forma:

$$
\begin{gathered}
V(w, r ; a)=k \\
c(w, r ; a)=1
\end{gathered}
$$

onde, $w$ corresponde aos salários e $r$ à remuneração do serviço local não comercializável entre as localidades (por exemplo, os alugueis). A primeira equação indica que os salários e aluguéis devem se ajustar nas diversas localidades, dadas as correspondentes amenidades, para equalização do bem-estar do trabalhador/consumidor entre tais localidades em um nível $k$; comum às localidade, de outra forma 
haveria incentivo à migração dos trabalhadores. A segunda reflete a igualdade entre o custo unitário de produção do bem $X$ (numerário) e seu preço (assumido igual a um) para todas as localidades, de outra forma as firmas teriam incentivos para migração para diferentes localidades. As equações permitem determinar conjuntamente $w$ e $r$ em função de a para dado nível de satisfação $k$; ou seja, permitem determinar os diferentes níveis de salários e aluguéis de equilíbrio para cada localidade (cada a). A Figura 1, ilustra tal determinação.

Figura 1 - Equilíbrio espacial para diferentes níveis de amenidades

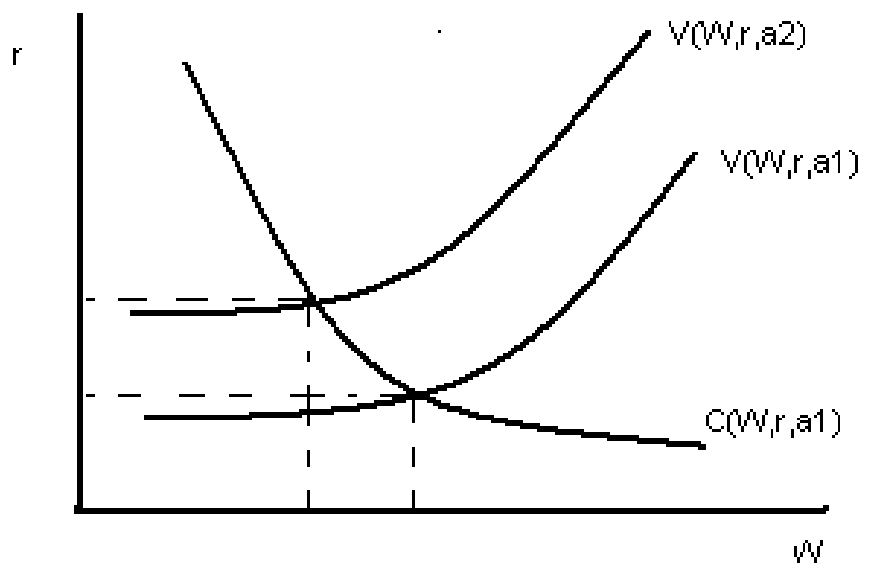

A curva $V(w, r ; a$.$) indica pares de r$ e $w$ que, para a dada dotação $a 1$ de amenidades, fornece o nível de satisfação comum entre as diferentes localidades. Por sua vez, a curva $c(w, r, a)$ indica os pares de $r$ e $w$ que satisfazem a condição da equação (2). A representação permite perceber, por exemplo, que localidades com amenidades elevadas afetando positivamente só o bem-estar $(a 2)$ terão salários menores e aluguéis mais elevados. Mas, caso tais amenidades também afetem positivamente as condições de produção (deslocamento para cima da curva $c($.$) ), tais localidades poderiam apresentar salários mais$ elevados e seguramente teriam aluguéis mais elevados.

Tais potenciais alterações salários podem ser apreendidas diferenciando-se as equações (1) e (2) e resolvendo-se para $d w / d a$ e $d r / d a$; neste caso as variações dos salários e aluguéis em relação às amenidades a no modelo são obtidas como:

$$
\frac{d w}{d a}=\frac{-V_{a} C_{r}+C_{a} V_{r}}{V_{w} C_{r}-V_{a} C_{w}} \mathrm{e} \frac{d r}{d a}=\frac{-V_{w} C_{a}+C_{w} V_{a}}{V_{w} C_{r}-V_{a} C_{w}}
$$

onde os subscritos indicam derivadas parciais. As equações expressam, assim, $d w / d a$ e $d r / d a$ em termos dos efeitos das amenidades de bem-estar e produtivas. No caso representado pela Figura 1 (deslocamento da relação $V($.$) para cima), ou seja, amenidades afetando apenas positivamente os con-$ sumidores, é possível, por exemplo, perceber que $\frac{d w}{d a}=\frac{-V_{a} C_{r}}{V_{w} C_{r}-V_{a} C_{w}}<0 \mathrm{e} \frac{d r}{d a}=\frac{C_{w} V_{a}}{V_{w} C_{r}-V_{a} C_{w}}>0$ (já que $V_{a}>0, C_{r}>0$ e $V_{w} C_{r}-V_{a} C_{w}>0$ ), ou seja, os salários seriam menores e aluguéis maiores nas localidades ou regiões mais bem dotadas com respeito a tais amenidades.

Ressalte-se, contudo, a possibilidade de existência de amenidades afetando positivamente as condições de produção, isto é, $C_{a}<0$, em áreas relativamente mal servidas com respeito a amenidades de consumo. Isto, ao elevar o incentivo para localização de firmas na localidade, fortaleceria a demanda por trabalho e potencialmente os salários e aluguéis. Por outro lado, caso a amenidade afete negativamente as condições de produção, os resultados poderiam ser salários e alugués menores. 
Mais formalmente, por exemplo, considerando o caso mais simples do efeito desta amenidade apenas na produção (assim, $V_{a}=0$ ), a partir das equações (3), percebe-se que, neste caso, $\frac{d w}{d a}=\frac{C_{a} V_{r}}{V_{w} C_{r}}>0$ e $\frac{d r}{d a}=\frac{-V_{w} C_{a}}{V_{w} C_{r}}>0$, ou seja, a localidade apresentando amenidades com efeitos positivos nas condições de produção e sem efeitos sobre o bem-estar apresentariam salários e aluguéis maiores.

Neste caso, mesmo não apresentando grandes atratividades naturais para os trabalhadores, seria possível encontrar centros urbanos ou localidades com salários e aluguéis relativamente mais elevados.

\subsection{Ranking de Qualidade de Vida a Partir de Preços Hedônicos}

O equilíbrio espacial apresentado acima permite, através de estimações paramétricas de equações para salários e aluguéis, obter um índice de qualidade de vida para as cidades e, assim, estabelecer um ranking para as localidades consideradas. Para tal, note-se que a diferenciação total da equação (1) com respeito ao nível de amenidade a permite obter:

$$
V_{r} \frac{d r}{d a}+V_{w} \frac{d w}{d a}+V_{a}=0
$$

Denotando-se, então, $P_{a}$ como a quantidade de renda necessária para compensar por uma pequena mudança no nível de amenidades a, isto é, $P_{a} \equiv \frac{V_{a}}{V_{w}}$, da equação (4) é possível obter:

$$
P_{a} \equiv \frac{V_{a}}{V_{w}}=-\frac{V}{r}_{V_{w}} \frac{d r}{d a}-\frac{d w}{d a}=h \cdot \frac{d r}{d a}-\frac{d w}{d a}
$$

onde a última igualdade foi obtida utilizando-se a identidade de Roy e $h$ representa a quantidade de serviços de moradia consumida.

Dado um conjunto de localidades, é possível, então, obter estimativas dos coeficientes destas amenidades nas equações de salários e aluguéis (preços hedônicos), respectivamente, $\frac{d w}{d a}$ e $\frac{d r}{d a}$, gerando-se estimativas de $P_{a}$, que podem ser utilizadas para construir índices de qualidade de vida para cada uma destas localidades. Mais especificamente, com um conjunto de $n$ amenidades e $m$ localidades, é possível obter m índices de qualidade de vida (IQV) na forma:

$$
I Q V_{j}=\sum_{i=1}^{n} P_{a_{i}} a_{i j}, \quad j=1,2, \ldots \ldots \ldots . m
$$

com $a_{i j}$ representando a disponibilidade da amenidade específica $i$ na localidade $j$.

Obtidos tais índices para as diferentes localidades consideradas, é possível estabelecer um ranking de qualidade de vida para este conjunto de amenidades. De fato, Rosen (1979) foi o pioneiro a desenvolver índices de qualidade de vida nos termos acima para os 15 maiores centros urbanos americanos. Mais especificamente, a partir de dados censitários, o autor estima preços implícitos para a poluição do ar, criminalidade, clima e indicadores das condições de mercado de trabalho e os utiliza junto com as disponibilidades locais destas amenidades para a construção de índices de qualidade de vida para os centros urbanos considerados. Posteriormente, Roback (1982), de forma pioneira, mostra como os salários e preços da terra são simultaneamente determinados e, estimando preços implícitos para um conjunto semelhante de amenidades, obtém um índice de qualidade de vida nos moldes da equação (6), acima, para cada uma das 20 maiores cidades americanas e estabelece um ranking para um conjunto de cidades americanas.

A partir dos trabalhos pioneiros destes dois autores, uma série de outras evidências foi gerada. Blomquist et alii (1988) expandem o universo de análise ao considerar 253 centros urbanos americanos e, nos mesmos moldes que Roback (1982), a partir de dados do ano de 1980, estimam preços implícitos de um conjunto de amenidades, utilizando-os na construção de índices de qualidade de vida. Gyourko e Tracy (1991) introduzem na análise os efeitos das condições fiscais das localidades, que poderiam afetar as decisões de localização de indivíduos e firmas. 
Mais recentemente, Srinivasan e Stewart (2004) e Blomquist (2005), seguindo expedientes semelhantes, estabelecem rankings de qualidade de vida, respectivamente, para municípios da Inglaterra e para municípios americanos. ${ }^{1}$ No primeiro caso, a partir de informações do ano de 1995, um índice similar àquele representado pela equação (6) é construído para os municípios ingleses a partir das dotações locais e da estimação de preços implícitos para um conjunto de amenidades naturais (precipitação pluviométrica, temperatura, dias de sol) e sociais (criminalidade, desemprego, densidade populacional, relação aluno/professor nas escolas). Já Blomquist (2005), a partir do mesmo conjunto de municípios utilizados por Blomquist et alii (1988), mas agora com um mais amplo conjunto de amenidades naturais (que inclui precipitação, umidade, velocidade do vento, distância da costa, dias de sol, dias de temperatura elevada e de temperatura baixa) e sociais (criminalidade, relação aluno/professor), após a estimação de preços implícitos para tais amenidades, obtém um ranking de qualidade de vida para tal conjunto de municípios bastante próximo àquele inicialmente gerado por Blomquist et alii (1988).

Uma vantagem importante deste conjunto de evidências e da metodologia utilizadas nos trabalhos acima citados deriva da utilização de pesos (preços estimados) que refletem preferências dos consumidores, afastando-se de escolhas arbitrárias destes pesos pelos pesquisadores. Contudo, como amplamente reconhecido (Kahn, 1995, Gyourko et alii, 1997), há um conjunto de sérias de dificuldades envolvidas na construção de rankings de qualidade para as localidades.

Primeiro e mais fundamentalmente, a estimativa consistente dos coeficientes das equações hedônicas está a exigir a observação e mensuração de todas as amenidades (naturais e sociais) relevantes. Isto porque a omissão de uma característica específica da localidade correlacionada com outros atributos considerados tornaria inconsistente o estimador dos coeficientes, o que, de acordo com a equação (6) acima, implicaria invalidação dos pesos do índice de qualidade de vida.

Um segundo problema está relacionado com o elevado grau de multicolinearidade entre muitos dos atributos locais, o que diminuiria a eficiência das estimativas. Analiticamente mais séria, uma terceira dificuldade deriva da assunção de homogeneidade espacial com respeito aos retornos às características individuais dos indivíduos, retornos estes que são utilizados na construção dos índices de qualidade de vida. Ou seja, não são consideradas as diferenças regionais de retorno aos atributos individuais (por exemplo, escolaridade), fundamentais para arbitragem espacial por parte dos indivíduos.

Por fim, deve-se sempre reconhecer as dificuldades na obtenção de indicadores exógenos de amenidades sociais, já que tais indicadores também tendem a refletir reações dos indivíduos ao ambiente social. Assim, por exemplo, ainda que se possa aceitar que centros urbanos com menor poluição ambiental apresentem um diferencial positivo de bem-estar (uma amenidade que estaria, pois, associada a menores salários), não se pode descartar a causalidade inversa, isto é, o padrão de consumo de indivíduos com salários mais elevados afetando os níveis de poluição ambiental urbana. Como na primeira dificuldade apontada acima, tal problema de simultaneidade tornaria inconsistente o estimador dos coeficientes e, desta forma, levaria à invalidação dos pesos do índice de qualidade de vida.

\subsection{Ranking de Qualidade de Vida a Partir da Preferência Revelada}

Em função das dificuldades acima apontadas, Kahn (1995) propôs a obtenção de um ranking de qualidade de vida para diferentes localidades a partir da valoração das qualificações individuais dos agentes e de suas moradias em cada uma destas localidades e dos potenciais ganhos dos indivíduos com migrações para localidades alternativas.

Intuitivamente, a proposta se baseia na noção do equilíbrio obtido a partir da arbitragem espacial dos agentes com respeito às diferentes localidades consideradas, como exposto no início desta seção. Neste equilíbrio, como qualquer agente estaria indiferente quanto à localidade de residência, localidades que apresentem menores possibilidades individuais de consumo, dadas as características dos agentes e de suas moradias, apresentariam maiores disponibilidades de bens públicos (amenidades naturais e sociais)

\footnotetext{
${ }^{1}$ Para um survey dos principais trabalhos, veja-se Gyourko et alii (1997).
} 
e, assim, maior qualidade de vida. Desta forma, como estes menores níveis de consumo estão associados à renda e aos custos de moradia, as localidades com maiores níveis de amenidades (maior qualidade de vida) também seriam aquelas de menores ganhos potenciais com a migração das demais localidades.

A partir desta relação entre ganhos potenciais e qualidade de vida, a metodologia de Kahn (1995) propõe a obtenção de um ranking de qualidade de vida entre diferentes localidades a partir de três etapas. A primeira etapa corresponde à estimação, para cada localidade $j$, de equações de determinação da renda do trabalho e do custo de moradia (aluguel):

$$
\begin{gathered}
W_{i j}=X_{i} \beta_{j}+\epsilon_{i j} \\
A l_{i j}=Z_{i} \gamma_{j}+v_{i j} \quad j=1,2, \ldots, . n .
\end{gathered}
$$

onde, $W_{i j}$ corresponde ao salário (ou seu logaritmo) do indivíduo $i$ da localidade $j, X$ é um vetor de características individuais, $A l_{i j}$ corresponde ao aluguel (ou seu logaritmo) pago pelo indivíduo $i$ na localidade $j, Z$ é um vetor de características dos domicílios, $\beta$ e $\gamma$ vetores de parâmetros a estimar e $\epsilon_{i j}$ e $v_{i j}$ são dois termos de erros. O ponto importante a notar é que, diferentemente do levado a efeito na construção de índice de qualidade de vida a partir de preço hedônicos, aqui os retornos às características individuais e as influências das características dos domicílios no valor dos aluguéis (parâmetros das equações) são permitidos variar entre as localidades.

Na segunda etapa, os valores estimados dos parâmetros são utilizados para obtenção de estimativas de salários e aluguéis potenciais de todos os indivíduos em todas as diferentes localidades consideradas na avaliação. Especificamente, para cada indivíduo $i$ (de acordo com suas características e as características de sua moradia), seria obtido o salário e o aluguel preditos em todas as localidades $j$ :

$$
\begin{aligned}
& \hat{W}_{i j}=X_{i} \hat{\beta}_{j} \\
& A \hat{l}_{i j}=Z_{i} \hat{\gamma}_{j}
\end{aligned}
$$

Por fim, de posse de estimativas, para todos os indivíduos, de salários e aluguéis em todas as localidades, é possível construir um ranking de qualidade de vida entre as cidades a partir do registro do percentual de indivíduos que obteriam ganhos de renda e diminuição no aluguel migrando para determinada localidade. Neste sentido, considere-se n o número de localidades consideradas e indexe-se com $k$ o número de indivíduos em cada localidade $j$; é possível, então, gerar uma matriz $n \times \mathrm{x} n$ com elementos $(\mathrm{c}, \mathrm{j})$ representando o percentual de agentes que obteriam ganhos salariais e reduções de custos de aluguel com a migração para uma localidade c e definido como:

$$
k_{j}^{-1} \sum_{i=1}^{k_{j}} 1 .\left(\left(\hat{W}_{i c}-\hat{W}_{i j}\right)>0\right) * .1 .\left(\left(A \hat{l}_{i c}-A \hat{l}_{i j}\right)<0\right)
$$

Onde o indicador 1. ( ) assume valor igual a um, se a expressão entre parênteses é verdadeira, e zero, caso esta não vigore. Desta forma, o produto entre as funções indicadoras dos salários e aluguéis será igual a um caso o indivíduo ao migrar da localidade j para a localidade c se beneficie com elevação de salário e redução de aluguel; caso contrário, o resultado seria zero.

Considerando todo o universo de migrantes potenciais das demais localidades para uma localidade $c$, é possível mensurar o percentual total de indivíduos que ganhariam com migração para cada localidade. Kahn (1995) então propõe a associação entre tal percentual e a qualidade de vida de cada localidade: elevados percentuais, que significariam um relativo grande número de pessoas com ganhos potenciais de consumo, estariam negativamente associados à qualidade de vida das localidades. A intuição é ancorada no equilíbrio espacial apresentado na seção anterior: os indivíduos têm de ser compensados pela residência em localidades com baixos (elevados) níveis de bens públicos ou amenidades naturais 
e sociais, o que implicaria maiores (menores) percentuais de indivíduos de demais localidades com ganhos (perdas) no consumo de bens privados.

Sem depender de estimações paramétricas para as valorações das amenidades que, necessariamente, têm que considerar todas as amenidades locais e assumir preços semelhantes em diferentes localidades, a proposta de Kahn (1995) é bastante engenhosa: os ganhos potenciais já refletiriam todo o conjunto de amenidades sociais e naturais (positivas e negativas) presentes na diferentes localidades consideradas.

\subsection{Qualidade de Vida e Preferência Revelada: Considerando as Amenidades Pro- dutivas e os Diferenciais Regionais de Custo de Vida}

A despeito de conseguir contornar os problemas de construção de um ranking de qualidade de vida a partir de estimações paramétricas das equações para os salários e aluguéis, a proposta de Kahn (1995) representada pela equação (11) acima, ao se ater apenas nas externalidades de consumo, deixa de considerar um ponto fundamental no equilíbrio espacial apresentado na seção anterior: o impacto das amenidades sobre os custos de produção e, assim, sobre o incentivo à localização entre as diferentes localidades por parte das firmas. Este poderia ser o caso, por exemplo, da maior concentração de capital humano, e potenciais externalidades derivadas, em algumas localidades, o que pode servir de incentivo à migração de firmas e, assim, traria elevações tanto de salários como de aluguéis nestas localidades. Ao ignorar tais efeitos, a proposta de Kahn (1995) tenderia a superestimar (subestimar) a qualidade relativa das grandes (pequenas) metrópoles, já que dificilmente os indivíduos oriundos das pequenas metrópoles apresentariam simultâneos ganhos de salários e reduções de aluguéis quando da migração para os grandes centros.

Para contornar tal deficiência, propõe-se, aqui, uma extensão do argumento de Kahn (1995) representado pela equação (11): deve-se considerar no percentual de indivíduos com ganhos potenciais não apenas aqueles com simultâneos ganhos potenciais de salários e reduções potenciais de aluguéis, mas também aqueles indivíduos cujos ganhos potenciais de salário mais que compensem potenciais elevações dos aluguéis com a migração para outras localidades e os indivíduos com ganhos líquidos de renda derivados de diminuições simultâneas de salários e aluguéis. Formalmente, a equação (11) seria estendida para incorporar este conjunto adicional de indivíduos:

$$
k_{j}^{-1} \cdot\left\{\begin{array}{l}
\sum_{i=1}^{k_{j}} 1 \cdot\left(\left(\hat{W}_{i c}-\hat{W}_{i j}\right)>0\right) * .1 \cdot\left(\left(A \hat{l}_{i c}-A \hat{l}_{i j}\right)<0\right) \\
+\sum_{i=1}^{k_{j}} 1 .\left[\left(\hat{W}_{i c}-\hat{W}_{i j}\right)-\left(A \hat{l}_{i c}-A \hat{l}_{i j}\right)>0\right] * 1 \cdot\left(\left(A \hat{l}_{i c}-A \hat{l}_{i j}\right)>0\right)
\end{array}\right\}
$$

Note-se que o segundo somatório da expressão (12) corresponde ao número de indivíduos cujos ganhos de salários com a migração da localidade $j$ para a localidade $c$ compensam as elevações dos aluguéis com tal deslocamento. Além de se considerar todo o universo de indivíduos com ganhos potenciais no consumo de bens privados, tem-se em conta não apenas os efeitos das amenidades de bem-estar, que implicariam salários menores e aluguéis maiores nas localidades com elevada qualidade de vida, mas também os efeitos das amenidades sobre os custos de produção, que, se positivos, implicariam salários e aluguéis maiores nas localidades com maior presença destas. Em maior acordo com o equilíbrio espacial exposto na seção anterior, a metodologia proposta evita a possível superestimação (subestimação) da qualidade de vida das maiores (menores) localidades. Nas evidências apresentadas a seguir, ambas as propostas são comparadas.

Uma questão adicional também não considerada por Kahn (1995) diz respeito aos diferenciais de custos de vida entre as localidades consideradas no que diz respeito a bens e serviços tradables e demais non-tradables que não os aluguéis. Como mostraram Azzoni et alii (2000, 2003), ao menos no caso brasileiro, há consideráveis diferenciais de custo de vida entre as regiões metropolitanas do país. 
A presente investigação considera tais diferenciais na determinação do ranking de qualidade de vida entre as regiões metropolitanas a partir de dois expedientes, ambos utilizando a metodologia de Azzoni et alii (2003). Primeiro, utiliza a equação (12) acima para a construção do ranking depois de corrigir os salários de acordo com os diferenciais de custo de vida que excluem os preços dos aluguéis. Segundo, ao corrigir os salários das regiões metropolitanas para os diferenciais de custo de vida considerando todos os bens e serviços (inclusive os aluguéis), obtém, para cada região metropolitana, o percentual dos indivíduos com ganhos de renda com migração potencial, formalmente:

$$
k_{j}^{-1} \sum_{i=1}^{k_{j}} 1 .\left(\left(\hat{W}_{i c}^{a}-\hat{W}_{i j}^{a}\right)>0\right)
$$

onde, agora, $\hat{W}_{i c}^{a}$ e $\hat{W}_{i j}^{a}$ representam os salários estimados ajustados para diferenciais de custo de vida nas regiões metropolitanas, respectivamente, de destino e de origem. Note-se que a equação (13) considera não apenas os diferenciais regionais de custo de vida com respeito aos bens e serviços tradables, mas também inclui os diferenciais regionais com respeito aos aluguéis.

Não menos importante, o ajuste por índice de custo de vida, que considera os pesos efetivos dos diferentes tipos de gastos no orçamento dos indivíduos, o que inclui os gastos com aluguéis, permite maior aproximação em relação aos diferenciais de poder de compra entre as RMs. De acordo com a expressão e em sintonia com o equilíbrio espacial, a localidade mais bem classificada apresentaria o menor percentual de indivíduos com ganhos de renda, considerados os salários ajustados.

\section{UM RANKING DE QUALIDADE DE VIDA PARA AS REGIÕES METROPOLITANAS DO BRA- SIL}

Nesta seção são apresentados os primeiros conjuntos de resultados a respeito da ordenação das RMs do Brasil a partir de seus níveis de qualidade de vida, de acordo com a metodologia proposta neste trabalho. As evidências são apresentadas na segunda subseção após a descrição dos dados utilizados.

\subsection{Base de Dados}

Na obtenção de um ranking de qualidade de vida paras as regiões metropolitanas brasileiras, de acordo com a proposta de Kahn (1995) e com a extensão proposta com a equação (12), foram utilizadas, inicialmente, informações da Pesquisa Nacional por Amostra de Domicílio (PNAD) do ano de 2004 do IBGE.

As características dos indivíduos incluídos nas amostras seguem de perto aquelas sugeridas por Kahn (1995); a idéia é considerar indivíduos com capacidade potencial de arbitragem quanto aos locais de moradia, cuja principal motivação para escolha do local de residência possa ser os diferenciais de bem-estar entre as localidades e que vivem em mercados de trabalhos não muito diferenciados. Desta forma, como primeira escolha, ao invés de comparar centros urbanos dos estados, o artigo considera as seguintes nove regiões metropolitanas classificadas pela PNAD: Belém, Fortaleza, Recife, Salvador, Belo Horizonte, Rio de Janeiro, São Paulo, Curitiba e Porto Alegre. Exclui-se, dadas as características distintivas relacionadas à presença da administração pública, portanto, o Distrito Federal.

Para cada região metropolitana, utilizou-se uma amostra formada por pessoas do sexo masculino, que estavam ocupadas, que trabalhavam mais de 15 horas semanais no trabalho principal e que eram chefes do domicílio. Além disto, dada a maior heterogeneidade setorial, foram excluídos indivíduos que trabalhavam em atividades agropecuárias. Por fim, em virtude da metodologia utilizada, seguiu-se o expediente de Kahn (1995) e foram incluídos na amostra apenas os indivíduos que pagavam aluguel 
pelos serviços de moradia. Tais escolhas acima implicaram amostras com tamanhos de 154 indivíduos (RM de Belém) a 697 indivíduos (RM de São Paulo) para as RMs do país. ${ }^{2}$

Como determinantes do salário do trabalho principal (equação (7)), foram utilizadas variáveis de características pessoais e de ocupação. No primeiro grupo, foram incluídas variáveis de capital humano representadas pela escolaridade e idade e as características individuais quanto à raça. Para apreender os diferentes níveis de escolaridade, foram considerados seis grupos de indivíduos: menos de um ano de estudos (categoria de referência nas estimativas), 1 a 3 anos de estudos, 4 a 7 anos de estudos, 8 a 10 anos de estudo, 11 a 14 anos de estudos e 15 ou mais anos de estudos. Por sua vez, a idade, considerada em anos, foi considerada em nível, além de um termo quadrático para apreender possíveis retornos decrescentes. Já as características pessoais de raça foram consideradas a partir de dois grupos: indivíduos das raças branca e não-branca (categoria de referência nas estimativas).

Quanto às características ocupacionais, foram considerados os ramos de atividade e posição dos indivíduos na ocupação. Os ramos de atividades utilizados nas estimativas foram classificados em quatro grupos: indústria (categoria de referência nas estimativas), construção, comércio e serviços. Com respeito às características da posição na ocupação, estas foram agrupadas em seis categorias: empregados sem carteira de trabalho (categoria de referência), empregados com carteira de trabalho, funcionário público ou militar, empregador e conta-própria.

Já para os determinantes dos aluguéis (equação (8)), as variáveis consideradas correspondem ao tipo ou categoria de moradia, se casa ou apartamento (categoria de referência nas estimativas), o material da construção do imóvel, a partir das categorias alvenaria (categoria de referência nas estimativas) ou demais materiais, o número de banheiros e o número de cômodos do domicílio. ${ }^{3}$

\subsection{Ordenação das Regiões Metropolitanas do Brasil Segundo a Qualidade de Vida}

A primeira etapa da construção corresponde a estimações das equações (7) e (8) para cada região metropolitana, obtidas através do estimador de Mínimos Quadrados Ordinários. Considerando-se como variável dependente a renda do trabalho, a Tabela 1, apresenta os resultados obtidos para a primeira destas equações em cada região metropolitana.

Os resultados apresentados na tabela 1, de forma geral, não representam novidades, sendo típicos de equações mincerianas tradicionais. Numa comparação entre as regiões metropolitanas do país, é possível destacar, contudo, algumas diferenças regionais. Considerando-se as características pessoais, note-se, primeiro, o mais elevado retorno relativo à educação para trabalhadores com 15 ou mais anos de estudos presente nas regiões metropolitanas das regiões Norte e Nordeste. Por sua vez, diferenciando-se da maioria das demais RMs, para as RMs da região Sul os retornos educacionais são estatisticamente significantes apenas para os níveis educacionais mais elevados, o que é consistente com a maior homogeneidade de escolaridade de sua população. Perceba-se também, a significativa vantagem de pertencer à cor branca para o caso particular da região metropolitana de Salvador. Tal evidência é de particular influência neste artigo, uma vez que a presença da população branca é relativamente maior nas demais RMs do país que na RM de Salvador, o que, como se nota adiante e dado o cálculo do ganho potencial com migração, afeta negativamente a posição desta referida RM no ranking obtido.

Com respeito às características ocupacionais, é possível anotar o elevado retorno da ocupação na atividade industrial em relação às três demais atividades presentes nas regiões metropolitana de Recife e

\footnotetext{
${ }^{2}$ Tais valores, a partir dos pesos presentes nos microdados da PNAD, permitem obter amostras expandidas de 26.860 e 627.582 indivíduos, respectivamente, para as RMs de Belém e São Paulo. Na obtenção dos percentuais de indivíduos com ganhos ou perdas com migração, foram consideradas sempre as amostras espandidas, uma vez que estas retratam os respectivos universos dos indivíduos.

${ }^{3}$ Infelizmente, não consta nas informações da PNAD o ano de construção das edificações. Apenas esta variável difere o presente conjunto das variáveis daquele considerado por Kahn (1995).
} 
Tabela 1 - Estimativas para a equação dos Salários - Variável Dependente é o log. da Renda do Trabalho $-2004$

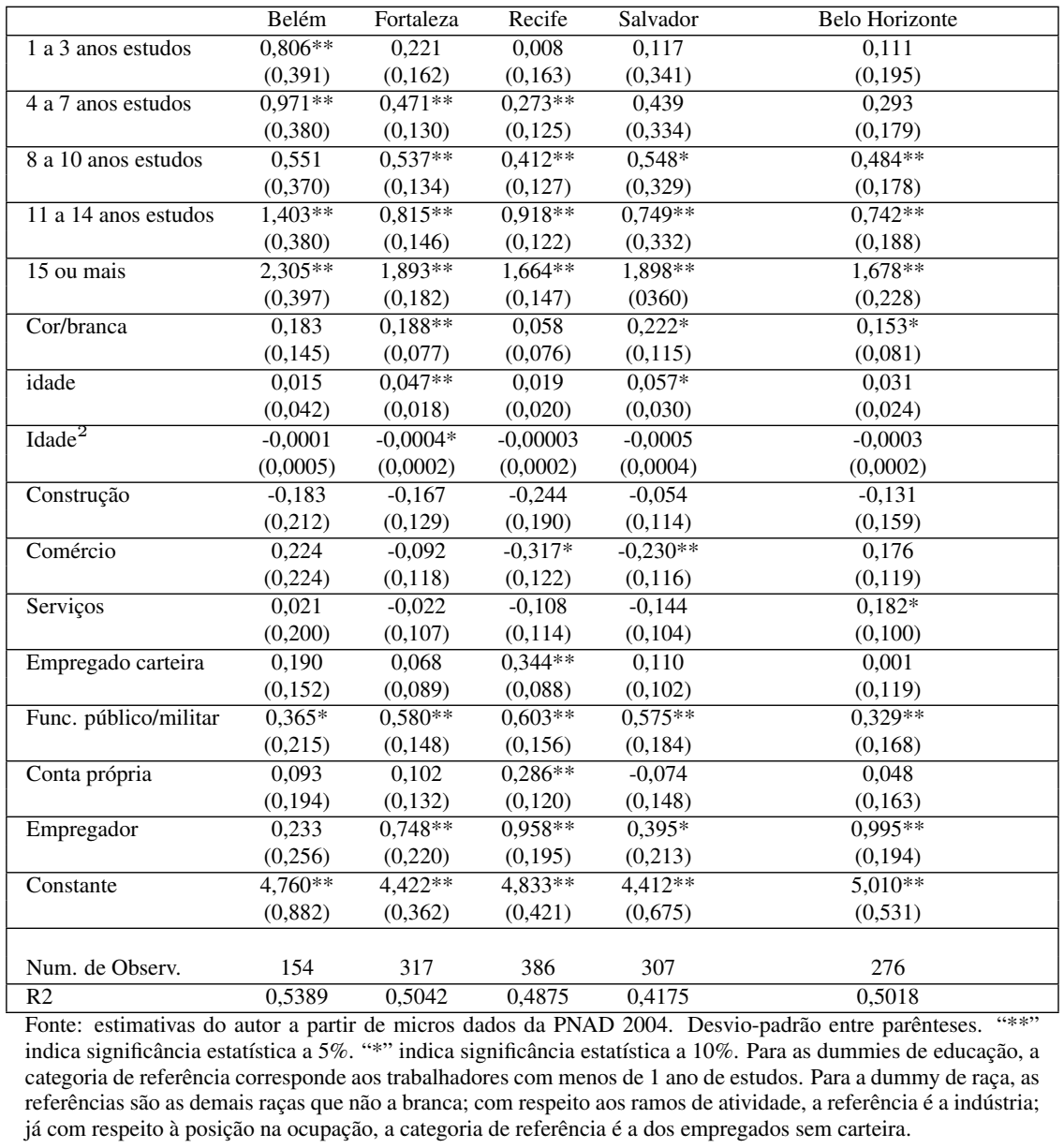

Salvador no Nordeste, uma diferenciação que é bem menos marcada nas demais regiões metropolitanas do país. Por fim, também para o caso das regiões metropolitanas do Nordeste, é notável o relativamente mais elevado retorno da ocupação do setor público em relação à situação de empregado sem carteira, o que é consistente com a maior precariedade da situação dos empregados sem carteira na região e com a maior importância relativa do setor público como empregador.

Nas Tabelas 3 e 4, são apresentadas as estimativas para a equação dos aluguéis (equação (8)) para as mesmas nove regiões metropolitanas.

Note-se que apesar do reduzido número de variáveis explicativas, as regressões apresentam um significativo coeficiente de determinação. Além disto, as estimativas para as diferentes RMs apresentam-se, de forma geral, bastante similares quanto aos sinais dos coeficientes estimados. Em particular, percebase que, em todas as regiões metropolitanas, os aluguéis tendem a ser maiores para apartamentos que para casas e, de forma geral, um maior número de banheiro e de cômodos implica também aluguéis mais elevados. Por fim, construções de alvenaria, em geral, se traduzem em aluguéis mais elevados.

De posse das estimativas dos parâmetros para as equações dos salários e aluguéis para todas as regiões metropolitanas, procede-se então a segunda e terceira etapas: para cada indivíduo de cada região metropolitana são estimados os salários e aluguéis potenciais que seriam, respectivamente, recebidos e 
Tabela 2 - Estimativas para a equação dos Salários - Variável Dependente é o log. da Renda do Trabalho $-2004$

\begin{tabular}{|c|c|c|c|c|}
\hline & Rio de Janeiro & São Paulo & Curitiba & Porto Alegre \\
\hline \multirow[t]{2}{*}{1 a 3 anos estudos } & $-0,154$ & 0,168 & $-0,225$ & 0,063 \\
\hline & $(0,138)$ & $(0,130)$ & $(0,294)$ & $(0,437)$ \\
\hline \multirow[t]{2}{*}{4 a 7 anos estudos } & $-0,145$ & $0,262 * *$ & 0,108 & 0,0001 \\
\hline & $(0,134)$ & $(0,108)$ & $(0,249)$ & $(0,399)$ \\
\hline \multirow[t]{2}{*}{8 a 10 anos estudos } & 0,11 & $0,462 * *$ & 0,138 & 0,057 \\
\hline & $(0,133)$ & $(0,112)$ & $(0,248)$ & $(0,397)$ \\
\hline \multirow[t]{2}{*}{11 a 14 anos estudos } & $0,460 * *$ & $0,688 * *$ & $0,483^{*}$ & 0,428 \\
\hline & $(0,135)$ & $(0,113)$ & $(0,264)$ & $(0,400)$ \\
\hline \multirow[t]{2}{*}{15 ou mais } & $1,114^{* *}$ & $1,552 * *$ & $1,441 * *$ & $1,004 * *$ \\
\hline & $(0,155)$ & $(0,142)$ & $(0,295)$ & $(0,407)$ \\
\hline \multirow[t]{2}{*}{ Cor/branca } & $0,178 * *$ & $0,153 * *$ & 0,054 & 0,111 \\
\hline & $(0,058)$ & $(0,043)$ & $(0,105)$ & $(0,084)$ \\
\hline \multirow[t]{2}{*}{ idade } & $0,052 * *$ & $0,049 * *$ & 0,04 & 0,014 \\
\hline & $(0,016)$ & $(0,014)$ & $(0,025)$ & $(0,017)$ \\
\hline \multirow[t]{2}{*}{ Idade2 } & $-0,0005^{* *}$ & $-0,0005 * *$ & $-0,0004$ & $-0,0001$ \\
\hline & $(0,000)$ & $(0,000)$ & $(0,000)$ & $(0,000)$ \\
\hline \multirow[t]{2}{*}{ Construção } & $-0,219^{* *}$ & $-0,172 *$ & $-0,156$ & $-0,174 *$ \\
\hline & $(0,110)$ & $(0,088)$ & $(0,175)$ & $(0,101)$ \\
\hline \multirow[t]{2}{*}{ Comércio } & $-0,115$ & $-0,086$ & $-0,012$ & $-0,041$ \\
\hline & $(0,103)$ & $(0,062)$ & $(0,134)$ & $(0,103)$ \\
\hline \multirow[t]{2}{*}{ Serviços } & 0,07 & $-0,038$ & 0,058 & 0,047 \\
\hline & $(0,090)$ & $(0,058)$ & $(0,110)$ & $(0,080)$ \\
\hline \multirow[t]{2}{*}{ Empregado carteira } & $0,168^{*}$ & $0,162 * *$ & $-0,009$ & $0,141^{*}$ \\
\hline & $(0,100)$ & $(0,063)$ & $(0,181)$ & $(0,081)$ \\
\hline \multirow[t]{2}{*}{ Func. público/militar } & $0,338^{* *}$ & $0,337 * *$ & $-0,045$ & $0,406^{* *}$ \\
\hline & $(0,126)$ & $(0,104)$ & $(0,243)$ & $(0,143)$ \\
\hline \multirow[t]{2}{*}{ Conta própria } & $0,203^{*}$ & $0,280 * *$ & $-0,056$ & $0,257 * *$ \\
\hline & $(0,117)$ & $(0,079)$ & $(0,239)$ & $(0,104)$ \\
\hline \multirow[t]{2}{*}{ Empregador } & $0,747 * *$ & $0,830 * *$ & $0,570 * *$ & $0,753^{* *}$ \\
\hline & $(0,171)$ & $(0,127)$ & $(0,253)$ & $(0,164)$ \\
\hline \multirow[t]{2}{*}{ Constante } & $5,055^{*}$ & $4,889 * *$ & $5,340 * *$ & $5,821 * *$ \\
\hline & $(0,323)$ & $(0,287)$ & $(0,482)$ & $(0,490)$ \\
\hline Num. de Observ. & 477 & 697 & 232 & 395 \\
\hline $\mathrm{R} 2$ & 0,4555 & 0,4521 & 0,407 & 0,3935 \\
\hline
\end{tabular}

Fonte: estimativas do autor a partir de micros dados da PNAD 2004. Desvio-padrão entre parênteses. “**" indica significância estatística a 5\%. "*” indica significância estatística a 10\%. Para as dummies de educação, a categoria de referência corresponde aos trabalhadores com menos de 1 ano de estudos. Para a dummy de raça, as referências são as demais raças que não a branca; com respeito aos ramos de atividade, a referência é a indústria; já com respeito à posição na ocupação, a categoria de referência é a dos empregados sem carteira.

Tabela 3 - Estimativas para a Equação dos Aluguéis - Variável Dependente é o log. do Aluguel Mensal $-2004$

\begin{tabular}{|lccccc|}
\hline & Belém & Fortaleza & Recife & Salvador & B.Horizonte \\
\hline Casa/apartamento & $-0,435^{* *}$ & $-0,269^{* *}$ & $-0,319^{* *}$ & $-0,263^{* *}$ & $-0,421^{* *}$ \\
& $(0,112)$ & $(0,078)$ & $(0,065)$ & $(0,057)$ & $(0,066)$ \\
& $-0,266^{* *}$ & $-0,192^{* *}$ & $-0,243^{* *}$ & $-0,168^{* *}$ & 0,017 \\
\hline Material: demais/alvenaria & $(0,091)$ & $(0,092)$ & $(0,053)$ & $(0,053)$ & $(0,054)$ \\
\hline Num. cômodos & $0,206^{* *}$ & $0,078^{* *}$ & $0,133^{* *}$ & $0,161^{* *}$ & $0,134^{* *}$ \\
& $(0,027)$ & $(0,021)$ & $(0,017)$ & $(0,023)$ & $(0,017)$ \\
\hline Num. banheiros & $-0,012$ & $0,305^{* *}$ & 0,109 & $0,388^{* *}$ & $0,126^{* *}$ \\
& $(0,074)$ & $(0,055)$ & $(0,069)$ & $(0,071)$ & $(0,057)$ \\
\hline Constante & $4,870^{* *}$ & $4,512^{* *}$ & $4,636^{* *}$ & $4,122^{* *}$ & $4,742^{* *}$ \\
& $(0,141)$ & $(0,113)$ & $(0,145)$ & $(0,111)$ & $(0,086)$ \\
\hline \multirow{7}{*}{ Num. de Observ. } & 154 & 317 & 386 & 307 & 276 \\
\hline R2 & 0,6594 & 0,5229 & 0,6101 & 0,5863 & 0,5825 \\
\hline Fonte: Estimativas do autor a partir de dados da PNAD 2004. Desvio-padrão entre parênteses. “**” indica
\end{tabular}

significância estatística a 5\%. Para a dummy do tipo de moradia a categoria de referência é apartamento; para a dummy de material de construção, a categoria de referência é alvenaria. 
Tabela 4 - Estimativas para a Equação dos Aluguéis - Variável Dependente é o log. do Aluguel Mensal $-2004$

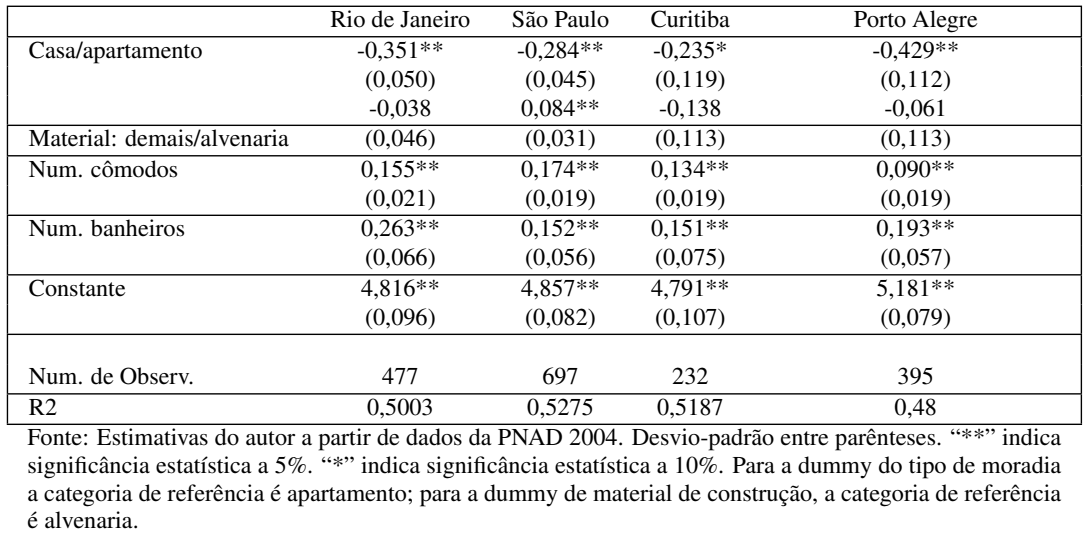

pagos caso este migrasse para demais regiões metropolitanas (equações 9 e 10). Em seguida, computase, para cada região metropolitana de destino, o percentual de indivíduos que apresentariam ganhos de consumo potencial, de acordo com as expressões (11) e (12). Com tais percentuais, é possível estabelecer um ranking de qualidade de vida para as regiões metropolitanas consideradas, uma vez que, dadas as compensações salariais e nos aluguéis, tais percentuais estão negativamente relacionados às disponibilidades de amenidades locais.

Os percentuais obtidos de acordo com a proposta de Kahn (1995) e com a extensão proposta neste artigo, juntamente com o cálculo da variação salarial percentual média exigida (caso positiva) ou aceita (caso negativa) com migração potencial, são apresentados na Tabela 5.

Tabela 5 - Ranking de Qualidade de Vida das Regiões Metropolitanas Brasileiras - Percentuais de pessoas que obteriam ganhos líquidos com migração e ganho líquido de renda estimado - 2004

\begin{tabular}{|lccc|}
\hline $\begin{array}{l}\text { Região } \\
\text { metropolitana } \\
\text { de destino }\end{array}$ & $\begin{array}{c}\text { \% com ganhos, } \\
\text { metodologia de } \\
\text { Kahn (1995) } \\
\text { estendida } \\
\text { (I) }\end{array}$ & $\begin{array}{c}\text { \% com ganhos, } \\
\text { metodologia de } \\
\text { Kahn (1995) } \\
\text { (II) }\end{array}$ & $\begin{array}{c}\text { Variação salarial } \\
\text { percentual } \\
\text { média } \\
\text { (III) }\end{array}$ \\
\hline Recife & 25,3 & $21,9(3)$ & -36 \\
Fortaleza & 29,8 & $26,6(6)$ & $-26,4$ \\
Rio de Janeiro & 32,9 & $16,1(2)$ & 4,6 \\
São Paulo & 35,1 & $10,1(1)$ & 18,5 \\
Salvador & 37,9 & $32,1(9)$ & $-15,3$ \\
Belém & 38,1 & $25,1(5)$ & $-7,1$ \\
Porto Alegre & 38,8 & $21,9(4)$ & 5,5 \\
Belo Horizonte & 40,7 & $31,1(8)$ & $-5,4$ \\
Curitiba & 41,9 & $27,5(7)$ & $-0,3$ \\
\hline
\end{tabular}

Fonte: Cálculos do autor a partir de dados da PNAD 2004. Os números entre parênteses indicam posição no ranking de acordo com o critério da coluna.

As duas colunas com percentuais permitem obter os rankings de qualidade de vida de acordo com a primeira metodologia proposta neste artigo (coluna (I)) e com a proposta inicial de Kahn (1995) (coluna (II)). Como esperado, os percentuais são maiores na metodologia proposta neste artigo, uma vez que também são consideradas as situações com ganhos líquidos associadas a elevações simultâneas de salários e aluguéis. Por exemplo, para o caso da região metropolitana de São Paulo, enquanto, segundo a proposta de Kahn (1995), apenas 10,1\% dos indivíduos das demais regiões metropolitanas ganhariam com a migração para esta região, de acordo com a proposta deste artigo, este percentual ficaria em torno de $35,1 \%$. Em acordo com as expectativas e favorecendo a proposta apresentada neste artigo, tal padrão 
de diferenciação tende a superestimar a qualidade de vida relativa das maiores metrópoles.

De fato, aplicando-se a metodologia de Kahn (1995), que ignora possíveis influências das amenidades produtivas sobre os salários e aluguéis, tem-se o ranking: 1. São Paulo, 2. Rio de Janeiro, 3. Recife, 4. Porto Alegre, 5. Belém, 6. Fortaleza, 7. Curitiba, 8. Belo Horizonte e 9. Salvador. Por outro lado, de acordo com a extensão proposta, que leva em conta o ganho líquido potencial em termos de consumo de bens privados, permitindo a influência das amenidades produtivas sobre os salários e aluguéis, obtém-se o seguinte ranking: 1. Recife, 2.Fortaleza, 3. Rio de Janeiro, 4. São Paulo, 5. Salvador, 6. Belém, 7. Porto Alegre, 8. Belo Horizonte e 9. Curitiba.

A comparação entre os dois rankings indica que apenas para a região metropolitana de Belo Horizonte há coincidência na posição relativa entre as regiões metropolitanas. Por outro lado, com a metodologia proposta, há reposicionamentos favoráveis às RMs de Fortaleza, Recife e Salvador e desfavoráveis para as demais regiões metropolitanas (exceto Belo Horizonte).

A partir do cálculo dos diferenciais salariais em caso de migração potencial, a coluna (III) da Tabela 5 apresenta a variação salarial percentual média com a migração dos indivíduos das demais RMs para a RM de referência, fornecendo, assim, um medida do ganho ou perda potencial envolvida. De acordo com os valores, por exemplo, os indivíduos das demais RMs estariam, em média, dispostos a abrir mão de 36\% dos salários caso residissem em Recife; por outro lado, caso o destino fosse a RM de São Paulo, em média, os indivíduos das demais RMs exigiriam um acréscimo de $18,5 \%$ dos salários. Destaque-se, também neste conjunto de evidências, as posições favoráveis das RMs nordestinas de Recife e Fortaleza.

Este último conjunto de evidência tem uma funcionalidade adicional. Perceba-se que embora para as duas RMs melhores classificadas inicialmente (Recife e Fortaleza) os valores desta última coluna indiquem posições bastante consistentes com aquelas do ranking da primeira coluna, o fato das RMs de São Paulo e Rio de Janeiro apresentarem, agora (coluna (III)), desempenhos bastante inferiores sugere que os diferenciais salariais nominais dificilmente podem ser tomados apenas refletindo diferenciais de amenidades entre as localidades. O que coloca sob suspeita também o ranking apresentado na coluna (I) da Tabela 5, uma vez que, exceto para os aluguéis, não são considerados os diferenciais de custo de vida entre as RMs.

\section{RANKING DE QUALIDADE DE VIDA PARA AS REGIÕES METROPOLITANAS: CONSIDE- RANDO OS DIFERENCIAIS DE CUSTO DE VIDA}

A observação acima indica a necessidade de se considerar explicitamente os diferenciais de custo de vida entre as RMs do país na construção de um ranking de qualidade de vida, flexibilizando-se, pois, a hipótese de equalização dos preços de bens e serviços comercializáveis entre as localidades, implícita no modelo de equilíbrio espacial da seção 2 do artigo. Como já explicitado, o ajuste dos salários para os diferenciais regionais de custo de vida é feito de duas formas. Primeiro, ajusta-se os salários da equação 12 por índices de preços que desconsideram os diferenciais de aluguéis; adicionalmente, utiliza-se o indicador dado pela equação 13, onde é calculado o percentual de indivíduos que apresentam ganho salarial com a migração com os salários já ajustados por índices regionais de custo de vida que incluem todos os bens e serviços do orçamento dos indivíduos, inclusive os aluguéis. Os resultados são apresentados na Tabela 6.

Os resultados apresentados nas colunas (I) e (IV) da Tabela 6 mostram a ordenação quando os percentuais são calculados com ajustes dos salários para todos itens da cesta de consumo, inclusive aluguéis (equação 13); já os valores indicados nas Tabelas 2 e 3 mostram ordenações quando salários por índices regionais de preços que não incluem o aluguel (equação 12). Há dois ganhos aparentes com tais correções. Primeiro, como esperado, os ganhos com correção para diferenciais regionais de custo de vida são bem menores que aqueles apresentados na Tabela 5, confirmando a importância dos ajustes salariais. Adicionalmente, em relação às ordenações da Tabela 5 ,há importantes evidências 
Tabela 6 - Ranking de Qualidade de Vida das Regiões Metropolitanas Brasileiras (RMs) - Percentuais de pessoas que obteriam ganhos líquidos com migração e ganho salarial médio. Valores ajustados para diferenciais de custo de vida entre as RMs - 2004

\begin{tabular}{|c|c|c|c|c|}
\hline $\begin{array}{l}\text { Região } \\
\text { metropolitana } \\
\text { de destino }\end{array}$ & $\begin{array}{l}\text { \% com ganhos, } \\
\text { salariais } \\
\text { líquidos }{ }^{a} \\
\text { (I) }\end{array}$ & $\begin{array}{l}\text { \% com ganhos, } \\
\text { metodologia de } \\
\text { Kahn (1995) } \\
\text { estendida }^{b} \\
\text { (II) }\end{array}$ & $\begin{array}{l}\text { \% com ganhos, } \\
\text { metodologia de } \\
\text { Kahn }(1995)^{b} \\
\text { (III) }\end{array}$ & $\begin{array}{c}\text { Variação salarial } \\
\text { percentual } \\
\text { média }^{a} \\
\text { (IV) }\end{array}$ \\
\hline Recife & 20,5 & $16,9(2)$ & $15,0(2)$ & $-17,3(1)$ \\
\hline Fortaleza & 21,4 & $19,3(3)$ & $18,7(3)$ & $-12,3(2)$ \\
\hline Rio de Janeiro & 43,8 & 23,9 (4) & $19,8(4)$ & $-1,9(4)$ \\
\hline Salvador & 44,2 & $38,2(6)$ & $34,0(6)$ & $-3,0(3)$ \\
\hline Curitiba & 51,0 & $35,0(5)$ & $29,6(5)$ & $1,9(5)$ \\
\hline Belo Horizonte & 52,4 & $41,4(7)$ & $36,0(7)$ & $3,0(6)$ \\
\hline São Paulo & 63,2 & $14,1(1)$ & $3,6(1)$ & $6,4(7)$ \\
\hline Porto Alegre & 65,4 & $46,3(8)$ & $36,0(8)$ & $7,3(8)$ \\
\hline Belém & 65,8 & $55,0(9)$ & $42,7(9)$ & $7,9(9)$ \\
\hline
\end{tabular}

Fonte: cálculos dos autores a partir de dados da PNAD 2004. Os números entre parênteses indicam posição no ranking de acordo com o critério da coluna. "a": salários ajustados para diferenciais de custo de vida, inclusive os diferenciais de alugueis. "b": salários ajustados para diferenciais de custo de vida, exclusive diferenciais de aluguéis.

a ressaltar. Entre as mais importantes, note-se que as RMs de Curitiba e Belo Horizonte, depois dos ajustes salariais, deixam de figurar entre as últimas colocadas (tabela 5). Por sua vez, as boas colocações das RMs litorâneas de Recife e Fortaleza antes obtidas (tabela 5) são repetidas, o que indica que seus posicionamentos não podem ser atribuídos aos seus menores custos de vida.

Em relação aos novos rankings obtidos, de forma geral, tais evidências com correções para diferenciais de custo de vida permitem perceber, por um lado, as boas colocações das RMs de Recife, Fortaleza e Rio de Janeiro (em todas as colunas, tais RMs estão entre as quatro mais bem posicionadas) e, por outro, as más performances relativas das RMs de Belém e Porto Alegre (sempre, as últimas colocadas). Como indicam os valores da coluna (I), por exemplo, depois de descontar os diferenciais de custo de vida entre as RMs, apenas cerca de 20,5\% dos habitantes das demais RMs teriam ganhos salariais com migração potencial para Recife, sendo de 65,8\% este percentual quando a RM de destino é Belém.

Com respeito às ordenações das colunas (I) e (IV), as ordenações das colunas (II) e (III), que consideram a correção dos salários por índices que excluem os aluguéis (considerados explicitamente através da equação 12), se diferenciam principalmente pela posição da RM de São Paulo (primeira colocada entre as RMs, de acordo com tais colunas, apesar da sétima colocação de acordo com as colunas (I) e (IV)). Tal reposicionamento possivelmente é explicado pelo menor peso dos aluguéis quando o índice geral de ajuste de preços é aplicado e pelo fato dos aluguéis na referida RM ser mais elevado. ${ }^{4}$

Os percentuais da coluna (IV) dão uma medida do ganho exigido ou perda aceita em termos salariais com a migração para as RMs, quando há correção para os diferenciais de custo de vida. Percebe-se, novamente, por um lado, as boas colocações das RMs de Recife, Fortaleza e, em menor grau, da RM do Rio de Janeiro e, por outro, as posições desfavoráveis de Belém e Porto Alegre. Mais especificamente, em média, os habitantes das demais RMs abririam mão de cerca de $17 \%$ e $12 \%$ de seus salários com migração, respectivamente, para as RMs de Recife e Fortaleza. No outro extremo, mesmo depois da correção para diferenciais de custo de vida, seria necessário um aumento salarial médio de cerca de $8 \%$ para demais habitantes das RMs do país migrarem para a RM de Belém.

\footnotetext{
${ }^{4}$ Com ajuste de salário para os diferenciais de preços das colunas (II) e (III), seria menor o número de indivíduos que ainda apresentaria ganho salarial para compensar aumento do aluguel com migração para São Paulo (equação 12), resultando no baixo percentual com ganhos nas referidas colunas.
} 


\section{RANKIG DE QUALIDADE DE VIDA PARA AS REGIÕES METROPOLITANAS: ALGUMAS HIPÓTESES}

Os rankings de qualidade de vida obtidos a partir das expressões (12) e (13), assim como aquele derivado da proposta de Kahn (1995), permitem contornar os problemas de variável omitida, diferentes preços dos fatores, multicolinearidade e endogeneidade de parte das amenidades presentes na construção de rankings de qualidade de vida obtidos a partir de estimações paramétricas dos preços das amenidades. Tal retorno, porém, não é obtido sem um custo importante: a impossibilidade de apontar exatamente que tipos de amenidades (bem-estar ou produção, positivas ou negativas) explicam a ordenação obtida para as localidades, ou seja, a metodologia não permite associar conclusiva e unicamente a posição de determinada localidade no ranking a um conjunto específico de amenidades de bem-estar, por exemplo.

Não obstante o reconhecimento desta limitação, nesta seção é feito um esforço no sentido de apontar a consistência e discutir potencias contradições dos resultados obtidos a partir das expressões (12) e (13) com evidências disponíveis para outros períodos. Neste sentido, o primeiro ponto a ressaltar é que, seja no ranking obtido a partir da expressão (12) na Tabela 6 (1. São Paulo, 2. Recife, 3. Fortaleza, 4. Rio de Janeiro, 5. Curitiba, 6. Salvador, 7. Belo Horizonte, 8. Porto Alegre e 9. Belém) ou no ranking derivado da expressão (13) na mesma tabela (1. Recife, 2. Fortaleza, 3. Rio de Janeiro, 4. Salvador, 5. Curitiba, 6. Belo Horizonte, 7. São Paulo, 8. Porto Alegre e 9. Belém), que considera mais adequadamente a participação das despesas de aluguéis, as RMs de Recife, Fortaleza e Rio de Janeiro estão sempre entre as quatro melhores colocadas. Em comum, tais RMs caracterizam-se pelas amenidades litorâneas, em aparente contraste com as RMs que ocupam em geral as últimas posições no referido ranking. Por sua vez, a relativamente boa situação nesta ordenação obtida para RM de São Paulo na coluna (II) da Tabela 6, que aparentemente enfraquece o argumento acima, pode estar associada às amenidades sociais derivadas de sua condição de maior metrópole do país (amenidades sociais, por exemplo, derivadas de acesso a serviços especializados) e ao peso dos aluguéis na obtenção da ordenação a partir da equação 12 .

Feitas estas observações, a avaliação das hipóteses levantadas com respeito ao ranking obtido a partir da expressão (13) para as regiões metropolitanas é levada a efeito em duas etapas. De início, são estimados os ganhos ou perdas salariais potenciais com a migração para as RMs de Recife, Fortaleza e Rio de Janeiro. Caso as boas posições no ranking destas RMs estejam associadas às amenidades litorâneas (naturais), são esperadas possíveis indiferenças entre tais RMs (sobretudo entre Fortaleza e Recife) e migrantes potenciais originários de RMs não-litorâneas abrindo mão de parte de seus salários com migração para estas três RMs.

Num segundo exercício, seguindo-se a mesma metodologia, obtém-se um ranking das mesmas regiões metropolitanas para o ano de 1993, e coteja-se o mesmo com aquele apresentado na Tabela 6 para 2004. Em uma situação de inexistência de alterações relativas significativas nas amenidades sociais entre as regiões metropolitanas, caso as amenidades naturais sejam de fato responsáveis pelas boas colocações das RMs de Recife, Fortaleza e Rio de Janeiro em 2004, em face na constância das mesmas no tempo, estas boas colocações deveriam se repetir em 1993.

\subsection{Variações Salariais Potencialmente Exigidas ou Aceitas com Migração: Indi- ferença entre as Regiões Metropolitanas Litorâneas mais bem Colocadas}

Os valores da Tabela 7, representam as variações percentuais médias dos salários com migração potencial para as RMs de Recife, Fortaleza e Rio de Janeiro, as três RMs mais bem colocadas de acordo com a coluna (I) da Tabela 6. Assim, por exemplo, enquanto, em média, os indivíduos que moram em São Paulo abririam mão de cerca de $22 \%$ do valor dos salários com migração para Recife, tal perda aceita é apenas de cerca de $4 \%$ caso o migrante potencial resida inicialmente em Fortaleza.

Duas evidências merecem destaque de acordo com os valores apresentados. Primeiro, note-se que, sem exceção, migrantes potenciais de RMs não-litorâneas aceitariam redução potenciais de salários 
Tabela 7 - Variações percentuais salariais médias exigidas/aceitas com migração (\%). Valores ajustados para diferenciais de custo de vida entre as RMs - 2004

\begin{tabular}{|l|ccc|}
\hline & \multicolumn{3}{|c|}{ Região Metropolitana de destino } \\
\hline Região Metropolitana de origem & Recife & Fortaleza & Rio de Janeiro \\
\hline Recife & - & 2,4 & 13,5 \\
\hline Fortaleza & $-3,9$ & - & 12,9 \\
\hline Rio de Janeiro & $-12,7$ & $-8,4$ & - \\
\hline Salvador & $-6,5$ & $-6,7$ & 6,6 \\
\hline Curitiba & $-16,3$ & $-9,6$ & $-1,0$ \\
\hline Belo Horizonte & $-18,2$ & $-14,9$ & $-5,4$ \\
\hline São Paulo & $-21,7$ & $-16,5$ & $-5,2$ \\
\hline Porto Alegre & $-19,8$ & -13 & $-5,6$ \\
\hline Belém & $-22,7$ & $-16,6$ & $-8,0$ \\
\hline
\end{tabular}

Fonte: Cálculos do autor a partir de micro dados da PNAD 2004.

quando o destino é uma das três RMs consideradas (embora a perda potencialmente aceita seja bem maior quando o destino é Recife ou Fortaleza, e relativamente menor no caso da RM do Rio de Janeiro). Segundo, consistente com as condições naturais semelhantes do litoral nordestino, há quase uma indiferença entre os indivíduos residentes na RM de Recife e na RM de Fortaleza. Com efeito, os habitantes da primeira RM exigiram um acréscimo médio de cerca de 2,4\% nos salários quando o destino é a RM de Fortaleza; já os habitantes desta última RM aceitariam uma redução percentual média de 3,9\% se o destino for a RM de Recife.

\subsection{Robustez Temporal: Comparação entre os Rankings de 1993 e 2004}

Como exercício final, na Tabela 8, são apresentados os percentuais de migrantes potenciais que apresentam ganhos líquidos com deslocamentos para as diferentes regiões metropolitanas brasileiras de acordo com as metodologias propostas neste artigo, agora, para o ano de 1993 (equações 12) e 13, respectivamente, colunas (II) e (I)) e a variação salarial percentual média exigida ou aceita de acordo com as RMs de destino.

De acordo com os ganhos salariais líquidos (coluna (I)), embora apenas Fortaleza e Curitiba preservem rigorosamente suas posições em relação ao ranking de 2004, de forma geral, os resultados mostram a consistência entre as ordenações de 1993 e de 2004. De fato, as três RMs melhores colocadas anteriormente (Recife, Fortaleza e Rio de Janeiro) continuam ocupando as três primeiras posições em 1993, embora a RM de Recife troque posição com a RM do Rio de Janeiro. Da mesma forma, as três RMs com piores colocações em 2004 (Belém, Porto Alegre e São Paulo) figuram entre as quatro RMs com piores colocações em 1993.

$\mathrm{Na}$ verdade, as quatro primeiras colocações e as quatro últimas em 1993 teriam sido preenchidas pelos mesmos conjuntos de RMs de 2004 caso as RMs de Salvador e Belo Horizonte não apresentassem alterações em seus posicionamentos entre os dois anos. Destes, o movimento de queda de posição relativa da RM de Salvador é o mais significativo (antes quarta colocada na ordenação de 2004, passa a ocupar a oitava posição em 1993) e está seguramente relacionado ao extremamente elevado retorno associado à característica pessoal de raça nesta RM (indivíduo da cor branca/não branca). ${ }^{5}$

Os valores apresentados nas colunas (II) e (III) da Tabela 8 apresentam-se em clara sintonia com o ranking da coluna (I). Como obtido para o ranking de 2004, a extensão da metodologia de Kahn (1995) proposta aponta uma posição mais favorável para a RM de São Paulo que aquela obtida com os ganhos

\footnotetext{
${ }^{5}$ As estimativas dos coeficientes das equações 7 e 8 para o ano de 1993 podem ser prontamente disponibilizadas pelos autores. De acordo com estas, na RM de Salvador, o salário dos indivíduos de cor branca era quase $50 \%$ maior que os slários dos indivíduos das demais etnias em 1993, um diferencial bem acima daqueles presentes nas demais RMs do país. Aqui, novamente, vale o argumento já expresso em relação à colocação relativa de Salvador em 2004, ou seja, o fato da maioria de habitantes das demais RMs ser de brancos faz com que estes tenham seu salários relativamente mais elevados com uma hipotética migração para a RM se Salvador, contribuindo decisivamente para rebaixar a posição desta RM na ordenação.
} 
Tabela 8 - Ranking de Qualidade de Vida das Regiões Metropolitanas Brasileiras (RMs) - Percentuais de pessoas que obteriam ganhos líquidos com migração e variação percentual salarial média. Valores ajustados para diferenciais de custo de vida entre as RMs - 1993

\begin{tabular}{|c|c|c|c|c|}
\hline \multirow[t]{2}{*}{$\begin{array}{l}\text { Região } \\
\text { metropolitana }\end{array}$} & \multicolumn{2}{|c|}{$\begin{array}{c}\text { Ganhos salariais } \\
\text { líquidos }^{a}\end{array}$} & \multirow{2}{*}{$\begin{array}{c}\text { Metodologia de Kahn (1995) } \\
\text { estendida }{ }^{b} \\
\% \text { com ganhos } \\
\text { (III) }\end{array}$} & \multirow{2}{*}{$\begin{array}{l}\text { Variação Salarial } \\
\text { percentual } \\
\text { média }^{a} \\
\text { (IV) }\end{array}$} \\
\hline & $\begin{array}{l}\% \text { com ganhos } \\
\text { (I) }\end{array}$ & $\begin{array}{c}\text { posição no ranking } \\
\text { em } 2004 \\
\text { (II) }\end{array}$ & & \\
\hline Rio de Janeiro & 32,2 & 3 & $25,2(1)$ & $-27,9(1)$ \\
\hline Fortaleza & 33,3 & 2 & $26,7(2)$ & $-26,8(3)$ \\
\hline Curitiba & 48,7 & 5 & $34,6(6)$ & $-1,7(5)$ \\
\hline Belém & 51,2 & 9 & $39,1(8)$ & $2,4(6)$ \\
\hline Porto Alegre & 51,9 & 8 & $34,0(5)$ & $3,1(7)$ \\
\hline Salvador & 54 & 4 & $46,5(9)$ & $8,4(8)$ \\
\hline São Paulo & 68,6 & 7 & $35,6(7)$ & $29,4(9)$ \\
\hline
\end{tabular}

salariais líquidos, mas preserva exatamente as quatro primeiras colocações da coluna (I). Por sua vez, quando se coteja com o ranking derivado dos ganhos salariais líquidos, os valores das variações salariais percentuais médias da coluna (III) indicam troca de posicionamento apenas entre a RM de Recife e a RM de Fortaleza.

\section{CONCLUSÕES}

A despeito da dimensão continental do Brasil e das reconhecidas disparidades de renda entre indivíduos de diferentes regiões do país, relativamente pouco esforço investigativo tem sido feito no sentido de associar tais disparidades às diferentes disponibilidades locais de amenidades ou bens públicos ou mesmo no sentido de cotejar as diferentes qualidades de vidas entre localidades. Este artigo, ao propor e aplicar para o conjunto de regiões metropolitanas do país uma nova metodologia de ordenar as localidades de acordo com as preferências reveladas dos indivíduos com respeito aos atributos locais, forneceu um conjunto de evidências que auxiliam o preenchimento desta lacuna.

Ao considerar tanto as influências de amenidades de bem-estar como produtivas, diferenciando-se das abordagens recentes de Monte (2004) e da Mata et alii (2006), foi possível estabelecer um ranking de qualidade de vida para as nove regiões metropolitanas do Brasil no ano de $2004 \mathrm{com}$ a seguinte ordenação: 1. Recife, 2. Fortaleza, 3. Rio de Janeiro, 4. Salvador, 5. Curitiba, 6. Belo Horizonte, 7. São Paulo e 8. Porto Alegre e 9. Belém.

Dadas as colocações obtidas pelas RMs do Nordeste e pela RM do Rio de Janeiro, o ranking obtido sugere que amenidades naturais litorâneas de bem-estar são importantes para as escolhas locacionais dos indivíduos do Brasil metropolitano. Embora o artigo não forneça respostas conclusivas a respeito, mostrou-se que as boas colocações das RMs de Recife, Fortaleza e Rio de Janeiro, supostamente explicadas pelas amenidades naturais de bem-estar (inalteráveis no tempo), são em geral mantidas quando o ranking é construído para o ano de 1993, o mesmo acontecendo com os posicionamentos (desfavoráveis) das RMs de Belém, Porto Alegre e, em menor grau, São Paulo.

É interessante notar que os posicionamentos obtidos para as metrópoles do Sul no ranking acima, em certa medida, conflitam com as evidências recentemente obtidas por da Mata et alii (2006) a respeito da qualidade de vida das cidades brasileiras. Mais especificamente, a partir de indicadores de infraestrutura urbana, de segurança e saúde e gastos do governo local, os autores obtêm evidências de que as cidades da região Sul do país oferecem maior qualidade de vida aos seus residentes que as cidades das demais regiões do país. 
Ao menos duas importantes explicações podem ser apontadas para tal desencontro, ambas favoráveis à metodologia empregada no presente artigo. Primeiro, diferentemente das evidências aqui obtidas, aquelas fornecidas por da Mata et alii (2006) consideram apenas amenidades sociais, ou seja, o juízo sobre a qualidade de vida das cidades não incorpora as amenidades relacionadas com o meio físico e a localização geográfica das cidades que parecem afetar de forma importante o bem-estar dos indivíduos num país continental como o Brasil. ${ }^{6}$ Em segundo lugar, como bem reconhecem os referidos autores, ao menos parte dos indicadores utilizados é potencial e conjuntamente determinada com o nível de renda dos indivíduos residentes das cidades consideradas. Neste sentido, tais indicadores, em grande parte, apenas refletiriam as condições mais favoráveis dos respectivos mercados de trabalhos e, assim, as características pessoais dos residentes. Por fim, é necessário anotar que enquanto o presente artigo considera apenas as regiões metropolitanas do país, da Mata et alii (2006) trabalham com todo o universo de cidades do país, o que, numa comparação de qualidade de vida entre estas, pode favorecer as cidades da região Sul (socialmente mais homogêneas) e desfavorecer principalmente o conjunto de cidades da região Nordeste, social e ambientalmente mais heterogêneas. ${ }^{7}$

\section{BIBLIOGRAFIA}

Azzoni, C. R., Do Carmo, H. E., \& Menezes, T. (2000). índice de custo de vida: Comparativo para as principais regiões metropolitanas brasileiras: 1981-1999. Estudos Econômicos, 30(1):165-186.

Azzoni, C. R., Do Carmo, H. E., \& Menezes, T. (2003). Comparações da paridade do poder de compra entre as cidades: Aspectos metodológicos e aplicação para o caso brasileiro. Pesquisa e Planejamento Econômico, 33(1):91-126.

Beeson, P. \& Eberts, R. (1989). Identifying productivity and amenity effects in interurban wages differentials. The Review of Economics and Statistics, 71:443-452.

Blomquist, G. (2005). Quality of life. In Arnott, R. \& McMillen, D., editors, A Companion to Urban Economics. Blackwell Publishing.

Blomquist, G., Berger, M., \& Hoehn, J. (1988). New estimates of quality of life in urban areas. American Economic Review, 78:89-107.

da Mata, D., Deichmann, U., Henderson, J. V., Lall, S. V., \& Wang, H. G. (2006). Um exame dos padrões de crescimento das cidades brasileiras. Technical Report 1155, IPEA, Brasília.

Gyourko, J., Kahn, M., \& Tracy, J. (1997). Quality of life and environmental comparisons. In Mills, E. S. \& Cheshire, P., editors, Handbook of Applied Urban Economics, Applied Urban Economics, volume 3. Elsevier, North-Holland.

Gyourko, J. \& Tracy, J. (1991). The structure of local public finance and the quality of life. Journal of Political Economy, 99:774-806.

Kahn, M. (1995). A revealed preference approach to ranking city quality of life. Journal of Urban Economics, 38:221-235.

Monte, D. (2004). The amenity costs of marginal climate change: The case of Brazil. Technical report, Yale University.

\footnotetext{
${ }^{6}$ Monte (2004) mostra que, para o conjunto das 11 maiores capitais do Brasil, as amenidades naturais (positivas e negativas) são efetivamente valoradas pelos residentes.

${ }^{7} \mathrm{O}$ que tende a diluir o peso das capitais nordestinas, relativamente mais bem situadas geográfica e socialmente, no total das cidades da região.
} 
Roback, J. (1982). Wages, rents na the quality of life. Journal of Political Economy, 90:1257-1288.

Roback, J. (1988). Wages, rents and amenities: Differences among workers and regions. Economic Inquiry, 26:23-41.

Rosen, S. (1979). Wages-based indexes of urban quality of life. In Mieszkowski, P. \& Straszheim, M., editors, Current Issues in Urban Economics. Johns Hopkins University Press, Baltimore.

Srinivasan, S. \& Stewart, G. (2004). The quality of life in england and wales. Oxford Bulletin of Economics and Statistics, 66(1):1-22. 